\title{
O INCIDENTE DE RESOLUÇÃO DE DEMANDAS REPETITIVAS NO CONTEXTO DO SISTEMA DE PRECEDENTES: ANÁLISE CRÍTICA DO FENÔMENO DA “COMMONLAWLIZAÇÃO" DO DIREITO BRASILEIRO
}

THE INCIDENT FOR RESOLUTION OF REPETITIVE CLAIMS IN THE CONTEXT OF THE PRECEDENT SYSTEM: CRITICAL ANALYSIS OF THE "COMMONLAWLIZATION" OF BRAZILIAN LAW

\section{Jesser Rodrigues Borges}

Graduado em Direito pela Universidade Feevale. Servidor do Ministério Público Federal. E-mail: jesserborges@gmail.com.

\section{Gabriel Joner}

Professor na Universidade Feevale. Mestre em Direito pela UNISINOS. Especialista em Direito Tributário pela UFRGS. Especialista em Direito Público pela FMP. Advogado. E-mail: gabrieljoner@feevale.br. 


\section{RESUMO}

O presente estudo tem por objetivo, sem a pretensão de esgotar o tema, analisar o Incidente de Resolução de Demandas Repetitivas, incluído pelo Novo Código de Processo Civil de 2015, sob a ótica do denominado sistema de precedentes e, ao final, propor uma análise crítica acerca da possível "commonlawlização" do direito brasileiro. Para tanto, buscou-se breves considerações históricas acerca dos institutos da common law e da civil law, na sequência, analisou-se tais institutos sob a ótica do Código de Processo Civil de 1973 e, ao final, a sua sistematização a partir do Novo Código de Processo Civil. Os mecanismos incorporados pelo Novo Código visam a amenizar a problemática atualmente enfrentada pelo Poder Judiciário, com o objetivo de proporcionar celeridade processual e segurança jurídica. Por fim, analisa-se o Incidente de Resolução de Demandas Repetitivas, propondo uma leitura crítica do fenômeno da "commonlawlização" do direito brasileiro, apontando a necessidade de cautela em relação aos mecanismos importados do direito estrangeiro, em especial, ao Incidente de Resolução de Demandas Repetitivas, a fim de dar-Ihes uma leitura conforme a Constituição Federal.

Palavras-chave: Novo Código de Processo Civil. Sistema de Precedentes. Common law. Civil law. Incidente de Resolução de Demandas Repetitivas.

\section{ABSTRACT}

The purpose of this study, without the pretension of exhausting the subject, is to analyze the Incident for Resolution of Repetitive Claims, included in the New Civil Procedure Code of 2015, under the perspective of the denominated precedents system and, at the end, to propose a critical analysis about the possible "communalization" of Brazilian law. ררתרTherefore, short historical considerations were sought on the common law and civil law institutes, followed by an analysis of these institutes from the point of view of the Code of Civil Procedure of 1973 and, finally, their systematization based on the New Code of Civil Procedure. The mechanisms incorporated by the New Code aim to alleviate the problems currently faced by the Judiciary, with the objective of providing procedural expediency and legal certainty. At the end, the Repetitive Demand Incident Incident is analyzed, proposing a critical reading of the phenomenon of "commonlization" of Brazilian law, pointing out the need for caution in relation to the mechanisms imported from foreign law, especially to the Incident of Resolution of Demands Repetitive, in order to give them a reading according to the Federal Constitution.

Keywords: New Civil Procedure Code. Precedents System. Common law. Civil law. Incident for Resolution of Repetitive Claims. 


\section{INTRODUÇão}

O presente estudo está inserido na temática do direito processual civil e tem como objetivo analisar o Incidente de Resolução de Demandas Repetitivas sob a ótica do denominado sistema de precedentes, o qual teria sido incluído pelo Novo Código de Processo Civil de 2015, partindo-se para uma análise crítica do fenômeno da "commonlawlização" do direito brasileiro, a partir do estudo de casos.

O estudo de tais mecanismos se mostra relevante, haja vista os atuais problemas enfrentados pelo Poder Judiciário na tentativa de suprir as necessidades sociais, em especial de proporcionar segurança jurídica e celeridade processual.

Tais problemáticas motivaram a elaboração deste estudo, o qual teve origem no Trabalho de Conclusão de Curso do Curso de Direito, cujo objetivo é verificar se, com o advento do Novo Código de Processo Civil, ocorreu o fenômeno denominado de "commonlawlização" do Direito Brasileiro, assim como analisar se tais mecanismos podem contribuir para a segurança jurídica e celeridade processual, sem que para isso seja necessário abrir mão do contraditório e da ampla defesa, indispensáveis no Estado Democrático de Direito.

Deste modo, no capítulo um, buscou-se uma retomada histórica das tradições do civil law e do common law, com o intuito de identificar o sistema de precedentes em sede de tais sistemas jurídicos, na sequência, analisou-se tal mecanismo em sede do direito brasileiro. No capítulo dois, tratou-se do Incidente de Resolução de Demandas Repetitivas, seu procedimento, efeitos e mecanismos destinados a garantir sua observância, na sequência, apresenta-se o estudo de casos, com o objetivo de verificar a utilização de tal mecanismo na prática forense.

Portanto, propõe-se uma leitura crítica do fenômeno da "commonlawlização" do direito brasileiro, expondo os principais problemas apresentados pela doutrina acerca do sistema de precedentes em contraponto aos princípios constitucionalmente estabelecidos.

\section{SISTEMA DE PRECEDENTES}

Com o advento do atual Código de Processo Civil, em especial o disposto em seu artigo 926, o qual determina, aos Tribunais, o dever de uniformizarem a jurisprudência, intensificaram-se as discussões doutrinárias acerca de uma possivel implantação, pelo direito brasileiro, de um sistema de precedentes. Há corrente doutrinária que sustenta a sua implantação, a fim de garantir a segurança jurídica e a celeridade processual. De modo diverso, autores apontam a inconstitucionalidade de tais mecanismos, demonstrando que o Brasil, cuja base é o civil law, não poderia simplesmente adotar institutos do common 
lawpela imposição das Cortes Superiores. Neste cenário, para uma análise mais acertada, serão analisadas as tradições jurídicas da civil law e da common law, assim como a sistemática de precedentes no Código de Processo Civil de 1973 e as modificações trazidas pelo atual CPC.

\subsection{AS TRADIÇÕES JURIDICAS DA COMMON LAW E CIVIL LAW: RAÍZES HISTÓRICAS}

Ensina Merryman (1998) que a tradição legal é um elemento cultural de determinada sociedade, de tal modo que reflete os ideais básicos que sustentam o modo de pensar, influenciando não apenas o pensamento jurídico, mas a sociedade como um todo. Assim, o Direito Romano tem como marco o ano de 450 a.C., data da publicação da lei das XII Tábuas, instrumento normativo instituído no período republicano, cujo principal objetivo era a restauração da segurança jurídica e a produção de igualdade social. Embora já houvesse um conjunto esparso de leis, a instituiç̧ão da lei das XII Tábuas é considerada um marco para formação do civil law.

Para Alves (2016, p. 16):

A lei das XII Tábuas resultou da luta entre a plebe e o patriciado. Um dos objetivos dos plebeus era o de acabar com a incerteza do direito por meio da elaboração de um código, o que viria refrear o arbítrio dos magistrados patrícios contra a plebe.

No final do século XI, na Itália, buscou-se uma retomada das principais normas do Direito Romano, movimento que ficou conhecido como renascimento social, o qual se desenvolveu nas principais universidades europeias. A partir de então, surgem várias escolas que estudam o corpus juris civilis, uma compilação das mais importantes normas do Direito Romano, posteriormente chamados de Glosadores. Por fim, no século XIX, as principais nações do continente europeu adotam códigos civis escritos, baseados principalmente no Código de Napoleão, de 1804, possuindo grande influência do corpus juris civilis, de Justiniano (MERRYMAN, 1989).

Observa-se que é característico da família jurídica da civil lawa formação de instrumentos normativos escritos, codificados em uma lei tendente a reger o comportamento de determinado grupo em sociedade. Assim, a norma será dotada de generalidade e abstração, pois é instituída com a finalidade de alcançar uma quantidade indeterminada de indivíduos, contemplando o maior número possível de situações fáticas, cuja incidência da norma determinará a solução jurídica para eventuais controvérsias, possuindo a 
norma, no âmbito desta tradição, supremacia em relação a outras fontes do direito, pois é principalmente por meio da lei que se busca, no âmbito desse sistema, a segurança jurídica (KELSEN, 2009, p. 5).

Assim, no âmbito dos sistemas jurídicos cuja base é o civil law, verifica-se a formação de uma estrutura legal codificada voltada a preservar a unicidade e a segurança desse sistema. Nesse sentido, há uma lei maior chamada de Constituição, da qual emanam diretrizes gerais do Estado e direitos fundamentais dos indivíduos que o compõem, leis infraconstitucionais e demais instrumentos normativos, como regra, oriundos de um Poder Legislativo constituído, com a função típica de legislar, e como uma cadeia ordenada de produção normativa estas são aplicadas a cada caso particular que é levado a juízo. Ressalta-se que a aplicação de tais normas é resultado da atividade interpretativa que inevitavelmente fará o juiz para encontrar a solução para um caso concreto que lhe é apresentado (OLIVEIRA, 2015).

Trata-se, portanto, a tradição de direito civil, da mais antiga e mais influente das tradições jurídicas, tendo se difundido por grande parte da Europa, toda a América Latina, partes da Ásia e da África, a partir de movimentos de colonização e recepção. Deste modo, a compreensão da tradição de direito civil é essencial para o entendimento das demais tradições jurídicas (MERRYMAN, 1989).

A tradição jurídica do direito comum, por sua vez, tem como marco inicial o ano de 1066, quando exércitos normandos derrotam e conquistam o reino da Inglaterra. A conquista normanda, por si só, não modifica o estado de direito e as normas que até então regiam a Inglaterra no período Anglo-saxônico, período esse que precede a conquista normanda, sendo que, após a conquista, continua-se aplicando o direito local, aplicam o direito canônico que era comum a toda a cristandade, os quais serão pouco a pouco substituídos por jurisdições senhoriais de uma nova ordem. Nesse período, ocorre o fim da era tribal e inicia-se, a partir de então, o feudalismo na Inglaterra. Deste modo, o common law passa a ser obra dos Tribunais Reais de Justiça (DAVID, 2014).

Na sequência, a tradição da common law passa a ser difundida com o desenvolvimento do império britânico e, consequentemente, a partir do movimento de colonização ocorrido na época. Na atualidade, a common law é a tradição jurídica vigente na Grã-Bretanha, Irlanda, Estados Unidos, Canadá, Austrália e Nova Zelândia, além de exercer grande influência em países da Ásia e da África (MERRYMAN, 1989).

Conforme Gilissen (2013, p. 20), o sistema da common law é um direito estruturado a partir das decisões jurisdicionais, sendo a jurisprudência sua fonte essencial representada por meio de precedentes, os quais irão influenciar sobremaneira os casos futuros.

Desta forma, verifica-se que enquanto a tradição jurídica da civil law, cuja base é o direito romanogermânico, pretende estabelecer normas de conduta, codificadas, a serem observadas pela sociedade, voltada a regrar o comportamento social futuro, a tradição jurídica da common law, de outro modo, cuja base é o direito inglês, é composta por juízes, os quais possuem a função de resolver litígios particulares, e 
possui regras menos abstratas, pois buscam solucionar o caso concreto apresentado em juízo, portanto, sua preocupação imediata é restabelecer a ordem violada e não a de regrar as bases sociais (DAVID, 2014).

Os ordenamentos jurídicos cuja base é o sistema da common law estão baseados no stare decisis, sistema pelo qual há um grau de vinculação dos precedentes aos casos futuros. Observados determinados critérios, um julgado poderá ser aplicado como precedente a um caso futuro quando houver semelhante objeto litigioso, ou seja, o precedente se torna a lei para o caso concreto. Assim, pretende-se garantir a estabilidade jurídica das decisões e a coesão de todo o sistema por meio da uniformização de entendimentos, utilizando-se a técnica dos precedentes (DIDIER, 2008).

Sendo assim, o que confere certeza jurídica e unidade para o ordenamento jurídico varia de acordo com o sistema ao qual se filia, de modo que sistemas cuja base é o civil law buscam legitimidade na norma legal escrita, para que esta estabeleça as condutas sociais adequadas, sendo a lei o referencial valorativo nesse sistema, a qual possui elevado grau de abstração e generalidade (DAVID, 2014). De outro lado, o common law busca a segurança jurídica a partir da formação de precedentes, valorizando o elemento histórico a partir da análise do conjunto de decisões anteriormente julgadas sobre o mesmo tema (NUNES, 2010).

\subsection{A SISTEMÁTICA DOS PRECEDENTES NO CÓDIGO DE 1973}

Uma vez delineadas as características que distinguem os sistemas jurídicos cuja formação está baseada nas famílias da civil law e da common law, verifica-se que a formação de uma sistemática de precedentes (com caráter vinculante) é característica predominante dos sistemas jurídicos cuja base é o common law. Nessa tradição jurídica há valorização maior do elemento histórico, no qual as normas são extraídas do costume, a partir da observância de julgados preexistentes, a fim de dar coerência a todo o sistema jurídico, denominado, na atualidade, de stare decisis.

A observância de um precedente está relacionada à necessidade de fundamentação das decisões jurisdicionais, que nasce com o fim das monarquias absolutistas, onde não se havia a obrigatoriedade de qualquer fundamentação para as decisões judiciais, que, como regra, eram imotivadas, baseadas na vontade do soberano que impunha sua vontade de modo arbitral, característico das ordálias (SHEID, 2009).

Ademais, com a superação do entendimento que permeou a Idade Média, de que a vontade do soberano era a vontade geral e que, portanto, suas decisões não necessitavam de qualquer motivação, surge o Estado Moderno. A partir de então, a legislação passa a representar a vontade geral, limitando até mesmo a vontade dos membros que compõem o Estado. Portanto, o juiz, como membro do Estado, está subordinado à legislação e deve motivar suas decisões (RAMIRES, 2010). 
Ressalta-se que, em razão da insuficiência legal para reger todos os comportamentos sociais possíveis, passou-se a utilizar os instrumentos da analogia e dos princípios gerais do direito, a fim de proporcionar a auto integração do direito. Portanto, o juiz intérprete não aplica apenas a lei ao caso concreto (subsunção do fato à norma), mas exerce atividade interpretativa quando integra o direito a fim de proporcionar-Ihe unidade e coesão (NEVES, 1972).

Nesse sentido, é esclarecedora a lição do doutrinador Miguel Reale (2014, p. 167), que define a jurisprudência como: "[...] a forma de revelação do direito que se processa através do exercício da jurisdição, em virtude de uma sucessão harmônica de decisões dos tribunais."

Adentrando na análise específica do código de processo civil de 1973, observa-se que já havia um capítulo destinado a tratar a uniformização da jurisprudência. Previa o parágrafo único do artigo 476 do antigo código, a exemplo, o incidente de uniformização da jurisprudência, mecanismo destinado a manter coerente a jurisprudência interna de determinado tribunal, suscitado quando houvesse julgamentos conflitantes, acerca da mesma matéria de direito no âmbito de uma mesma corte. Uma vez julgados, os fundamentos da decisão proferida no incidente possuíam vinculatividade quanto a mesma matéria suscitada (NERY, 1996, p. 853-854).

Ocorre que a jurisprudência, nesse ponto, possui apenas o caráter indicativo e não vinculante, com exceção de poucos mecanismos específicos. Diferentemente ocorre em um sistema de precedentes, no qual se permita que uma corte, de modo discricionário, forme entendimentos que irão vincular casos futuros. Os precedentes se constituem nos fundamentos determinantes para a solução de determinada questão levada a juízo, os quais possuirão generalização, obtida a partir do julgamento de casos em um colegiado, notadamente de uma Corte Suprema (MITIDIERO, 2017).

Sendo assim, verifica-se que o código de processo civil de 1973, embora tenha adotado mecanismos para manter coerente a jurisprudência nos tribunais, não adotou um sistema de precedentes com caráter vinculante, mas esta possibilidade se desenvolveu a partir da incorporação de normas do direito estrangeiro (MITIDIERO, 2017).

Observa-se um movimento de recepção, em especial de normas do norte americano. A exemplo, a adoção do sistema de freios e contrapesos, instituído a partir da Constituição de 1891, atribuindo-se importante papel ao poder judiciário, possibilitando que este exerça o controle de constitucionalidade dos atos emanados pelos demais poderes (ZANETI JR., 2016).

A Emenda Constitucional no 45 de 2004 representa sobremaneira este movimento, vez que fora fortemente influenciada pelo direito norte-americano e perpetrou uma profunda reforma no Poder Judiciário brasileiro, em especial no que tange à utilização de precedentes com força normativa, a exemplo disso destaca-se a instituição das súmulas vinculantes (ZANETI JR., 2016). 
Na visão de alguns doutrinadores, as súmulas vinculantes se constituem em verdadeiro precedente, haja vista que possui um comando normativo emanado pela corte suprema, advindo do entendimento consolidado a partir de reiteradas decisões, o qual possui caráter vinculante, vale dizer, obriga os juízos inferiores na tomada de suas decisões, pois é de observância obrigatória (REIS, 2005).

Portanto, verifica-se que o direito brasileiro está consolidado na família de direitos da civil law, haja vista que possui um ordenamento jurídico posto, com a grande maioria de suas normas escritas em uma Constituição Federal e em normas infraconstitucionais, as quais possuem generalidade e abstração, em vista de regrar comportamentos futuros da sociedade. Embora não houvesse, no âmbito do Código de Processo Civil de 1973, o estabelecimento de um sistema de precedentes, a partir do desenvolvimento histórico, em especial a partir da recepção de institutos do direito estrangeiro, tendo como auge a emenda constitucional $n^{\circ}$ 45/2004, passou-se a adotar mecanismos destinados a vincular juízos inferiores quanto aos entendimentos emanados pelas Cortes Supremas. Por fim, com o advento do Novo Código de Processo Civil, como se verá adiante, intensificou-se uma divergência doutrinária acerca da possibilidade de utilização, no direito brasileiro, de um sistema de precedentes.

\subsection{AS MODIFICAÇÕES TRAZIDAS PELO NOVO CPC}

Com o advento do Novo Código de Processo Civil, parcela da doutrina, formada por autores como Luiz Guilherme Marinoni, Daniel Mitidiero, Hermes Zaneti Jr. e Sérgio Arenhart, sustenta a possibilidade de serem atribuídos efeito vinculante aos julgados, de modo que, quando emanados pelas Cortes Superiores, tais decisões formarão precedentes. Em contraponto, outra parte da doutrina, formada pelos autores Lenio Streck, Igor Raatz, Maurício Ramires, Nelson Nery Junior, entre outros, sustenta que, em um sistema de civil law, como o nosso, não se pode permitir que precedentes sejam admitidos como fonte do direito, pois somente a lei, emanada pelo Poder Legislativo legitimamente constituído, possui o condão de estabelecer normas de conteúdo obrigatório, sob pena de ferir o princípio da legalidade perpetrado pela Constituição Federal.

A primeira corrente sustenta que, com o advento do Novo Código de Processo Civil, o sistema de precedentes passou a ser estruturado, partindo-se da premissa de que a lei como único instrumento normativo não é capaz de proporcionar a segurança jurídica, indispensável para o convívio em sociedade, haja vista que possui elevado grau de indeterminação. Assim, a aplicação do precedente nasce para promover a segurança jurídica, evitando julgados divergentes sobre a mesma temática. Deste modo, sustentam que o precedente deveria ser utilizado como instrumento para clarear a interpretação 
de determinada lei diante de um caso concreto, contribuindo para a unicidade do sistema de modo a proporcionar igualdade entre os jurisdicionados (SILVEIRO, 2017).

Aqueles que defendem o sistema de precedentes argumentam a necessidade de uma perspectiva reconstrutiva do sistema jurídico nacional, de modo a atribuir às Cortes Supremas a competência de interpretar a lei, produzindo teses em abstrato, com a finalidade de vincular os demais juízos a tais comandos normativos. Assim, estaria o direito brasileiro a adotar o stare decisis do sistema de common law (MITIDIERO, 2017).

Em contraponto, surgem doutrinadores, como Streck (2016a), os quais afirmam que o direito brasileiro, assentado sob a tradição da civil law, não pode ser transformado em um sistema de common lawpela obrigatoriedade de observância de precedentes, firmados por cortes de vértice, para eles, autores que defendem a "commonlawlização" do direito brasileiro querem substituir o direito posto (firmado na Constituição Federal e demais normas que compõem o nosso ordenamento jurídico) por um stare decisis, se utilizando de técnicas da common law. Pretendem decretar um sistema de teses e precedentes, proporcionando maior discricionariedade ao Poder Judiciário ao ponto de poder este decidir mesmo em contrário ao texto normativo.

O autor Ramires (2010, p. 44-45), por sua vez, deixa clara a importância de se manter íntegra e coerente a jurisprudência, a fim de proporcionar segurança jurídica e coesão nas decisões emanadas do Poder Judiciário, consolidando, por meio da tradição de julgados precedentes, a interpretação acerca de determinada matéria. Contudo, deixa claro que se deve utilizar a hermenêutica como técnica de superação do método subsuntivo, de modo que as decisões judiciais estejam devidamente fundamentadas, não se utilizando de meras reproduções de verbetes jurisprudências, sob pena de o precedente ser aplicado sem a devida análise dos fatos do caso concreto, fundamentando decisões apenas com base em ementas jurisprudências. Para o autor, tal posicionamento remete justamente ao anteriormente abordado, o qual adota o método subsuntivo "do precedente ao caso concreto", seria um retrocesso a utilização de um sistema de precedentes do modo como vem sendo proposto por parte da doutrina.

Assim, os doutrinadores Streck e Raatz (2016) apontam como problema central da teoria dos precedentes o argumento de que estariam, texto e norma, absolutamente separados. Sustentam que, embora haja uma diferença ontológica entre os dois conceitos, não é possivel ao interprete atribuir sentido, de forma arbitrária e discricionária, ao texto da lei, como se texto e norma pudessem sempre estar separados, como se o Poder Legislativo apenas elaborasse textos vagos e sem sentido.

Portanto, verifica-se que há necessidade de enfrentar o problema da insegurança jurídica e promover a unidade do direito. A partir desse ponto, parcela da doutrina sustenta que a solução para tais problemáticas seria a instituiç̧ão, supostamente ocorrida com o novo CPC, de um sistema de precedentes 
com a reconstrução de nosso sistema jurídico, nesse sentido, concordam Luiz Guilherme Marinoni, Daniel Mitidiero, Fredie Didier Jr., entre outros. De encontro a este pensamento, os autores Lenio Streck, Igor Raatz, Nelson Nery Junior, entre outros sustentam a inconstitucionalidade de se estabelecer, no Brasil, cuja base é o sistema da civil law, um sistema de precedentes com o intuito de vincular os juízos inferiores, a partir do julgamento de casos pelas Cortes de Vértice. Haja vista que se estaria outorgando, ao Poder Judiciário, a função de criar normas abstratas e gerais com caráter vinculante, ou seja, autorização para legislar, função esta que é atribuída constitucionalmente apenas ao Poder Legislativo, democraticamente eleito.

\section{INCIDENTE DE RESOLUÇÃO DE DEMANDAS REPETITIVAS}

O incidente de resolução de demandas repetitivas (IRDR) é o instrumento processual, previsto no Novo Código de Processo Civil, cujo objetivo é resolver, em definitivo, questão unicamente de direito em demandas repetitivas; mecanismo desenvolvido para solucionar demandas em massa, a partir do julgamento de caso paradigma (ou modelo), aplicando-se, aos demais casos, supostamente análogos, o mesmo entendimento, sob o fundamento de promover a segurança jurídica e prestar uma tutela jurisdicional isonômica. Não é por menos que, com o advento do novo código, parcela significativa da comunidade jurídica passou a discorrer acerca de eventual inconstitucionalidade de tal instituto.

\subsection{PROCEDIMENTO}

O Incidente de Resolução de Demandas Repetitivas é instrumento destinado a formar uma tese jurídica, a qual deverá ser aplicada aos casos, tanto presentes como futuros, que tratem da mesma questão de direito. Dotado, portanto, de efeito vinculante, tanto no âmbito do tribunal que julgou o incidente, como nos demais juízos a ele vinculados (MARINONI, 2016).

Prevê o artigo 976 do NCPC que a instauração do IRDR é cabivel quando preencher, simultaneamente, dois requisitos essenciais, quais sejam: "Efetiva repetição de processos que contenham controvérsia sobre a mesma questão unicamente de direito; e risco de ofensa à isonomia e à segurança jurídica" (BRASIL, 2015).

De acordo com Rossi (2015), tal instituto possui inspiração no direito alemão, lá denominado Musterverfahren, ou seja, procedimento-modelo ou de tese. Possivelmente, a busca por tal mecanismo possa ser atribuída ao desenvolvimento de uma sociedade complexa, onde ocorrem relações em massa, assim como à insuficiência de recursos e instrumentos capazes de solucionar os conflitos advindos 
dessas relações. Assim, supostamente, estaria garantida a economia processual, a segurança jurídica e a isonomia no julgamento.

A competência para o julgamento do IRDR, nos termos do artigo 977 e 978 do CPC/2015, é do tribunal, seja para o julgamento de demandas repetitivas suscitadas no primeiro grau de jurisdição ou quando estas já estiverem em grau recursal. O requerente deve direcionar o pedido de instauração ao presidente ou vice-presidente, e, na sequência, o incidente será distribuído ao órgão responsável. 0 regimento interno de cada tribunal deve atribuir competência para uniformização da jurisprudência a um ou mais órgãos colegiados, dentre estes será indicado, no regimento interno, um órgão competente para o julgamento do IRDR (MARINONI, 2016).

Prevê o artigo 982 do CPC/2015 que, uma vez admitido o incidente, caberá ao relator suspender os demais processos que versem sobre idêntica questão de direito, na mesma região em que fora suscitado. Poderá, ainda, requerer informações a órgãos, assim como deverá intimar o Ministério Público, oportunizando que este se manifeste no prazo de 15 dias. Além do mais, deve dar ampla publicidade da matéria, a fim de proporcionar a participação dos interessados (BRASIL, 2015).

Serão selecionados, por amostragem, dois ou mais casos para análise e julgamento. Os demais permanecerão sobrestados e, ao final, a estes será aplicada a mesma tese jurídica dos casos julgados. Não obstante, há possibilidade de a parte requerer o prosseguimento do seu processo, desde que demonstrada a distinção em relação aos demais casos (DIDIER JÚNIOR; CUNHA, 2016).

Adverte Abboud (2014) que o IRDR pode estar a violar o devido processo legal, vez que não há previsão de adequada participação dos litigantes abrangidos pelo IRDR, a fim de que esses efetivamente influenciem na decisão do incidente. Portanto, para garantir a constitucionalidade do novo instituto é necessário um controle, por parte do Poder Judiciário, na garantia da representatividade dos interesses do grupo envolvido no incidente.

O incidente deve ser julgado no prazo de um ano, a fim de atender à celeridade processual, haja vista que inúmeras demandas permanecerão suspensas até que ocorra seu julgamento. Assim, há previsão de preferência do IRDR sobre outros feitos do tribunal. Além do mais, transcorrido o prazo sem que haja julgamento do incidente, cassará de imediato a suspensão dos processos pendentes, exceto em casos relevantes, que justifiquem a sua manutenção, devendo ser fundamentado pelo relator (MARINONI, 2016).

Conclui-se que tal instrumento foi desenvolvimento para atender às demandas repetitivas, diante da multiplicação de litígios. O julgamento do IRDR é de competência dos tribunais, condicionada sua instauração aos requisitos da efetiva repetição de processos sobre mesma matéria de direito e ao risco de ofensa à isonomia e à segurança jurídica. Deste modo, uma vez delineado o procedimento, passaremos a analisar os efeitos do incidente de resolução de demandas repetitivas. 


\subsection{EFEITOS}

O Novo Código de Processo Civil atribui ao IRDR o efeito de estabelecer um padrão decisório para a resolução das demandas repetitivas apresentadas ao tribunal, assim como aos casos futuros sobre a mesma questão de direito. A partir desse entendimento, parcela da doutrina, entre os quais Fredie Didier Jr., Leonardo Carneiro da Cunha, Hermes Zaneti Jr., Sofia Temer, sustenta que a decisão do incidente é um precedente, pois dotada de eficácia vinculativa (TEMER, 2016).

Ocorre que, como bem adverte Nery (2015), o Poder Judiciário possui independência e autonomia em relação aos demais poderes, não havendo, portanto, hierarquia entre os três poderes nem mesmo entre os órgãos do próprio judiciário, exceto quando o tribunal exerce sua função recursal para reformar a decisão de primeiro grau recorrida. Assim, não há autorização constitucional para que tribunais superiores possam legislar por intermédio de orientações jurisprudenciais, salvo quando expressamente autorizados.

Ademais, há de se trazer à tona o problema da discricionariedade criada pelo instituto do sistema de precedentes, como o fazem Streck e Raatz (2016b, p.403):

\footnotetext{
Com efeito, diferentemente do common law, em que os precedentes não costumam ser pensados para resolver casos futuros, de modo que sua força vinculante será aquilatada somente no confronto com um novo caso, no Brasil os 'precedentes' nascem (são fabricados) para resolver os casos futuros e, com isso, evitar novas interpretações a respeito da lei. Afinal, o sentido atribuído aos textos normativos pela 'corte de precedentes' adquire, pela sua autoridade, força vinculante e, ironicamente, essa 'decisão' não dependerá de novas interpretações. Dito de outro modo, o precedente será aplicado por 'subsunção', bastando aos juízes nos casos futuros subsumirem os fatos ao 'precedente.'
}

No mesmo sentido, Ramires (2010) sustenta que o uso indiscriminado de precedentes para fundamentar casos futuros torna a jurisprudência fonte do direito, colocando-a no mesmo patamar da lei, dos princípios gerais do direito e dos costumes. Consequentemente, estaremos diante do problema da arbitrariedade jurisdicional, na qual se observam decisões antagônicas, as quais podem ser adaptadas por conveniência e oportunidade, elevadas ao status de lei em sentido stricto e, portanto, vinculantes aos juízos "inferiores". Nesse cenário, conclui o autor, que as decisões formadas a partir desses precedentes não estarão devidamente fundamentadas, desta forma serão consideradas nulas por vício de inconstitucionalidade. 
Portanto, o principal efeito do IRDR é a força vinculante, de modo a tornar a tese jurídica de observância obrigatória. Por essa razão há quem sustente a instituição de um sistema de precedentes, dentre os quais os autores Luiz Guilherme Marinoni, Daniel Mitidiero, Hermes Zaneti Jr. e Sérgio Arenhart. Não obstante, doutrinadores como Lenio Streck, Igor Raatz, Maurício Ramires e Nelson Ney Junior, entre outros, demonstram a inconstitucionalidade de se instituir, no Brasil, cuja base do ordenamento é o civil law, um sistema de precedentes, a partir de Cortes de Vértice, a qual teria a competência de tão somente interpretar a lei e formar teses jurídicas a serem aplicadas pelos juízos inferiores de modo automático.

\subsection{MECANISMOS PARA ASSEGURAR SUA OBSERVÂNCIA}

O Novo Código de Processo Civil estabeleceu o instituto da reclamação como mecanismo para assegurar a observância das teses fixadas por Tribunais Superiores. Estabelece o inciso IV do artigo 988 do NCPC que: "Caberá reclamação da parte interessada ou do Ministério Público para garantir a observância de enunciado de súmula vinculante e de precedente proferido em julgamento de casos repetitivos ou em incidente de assunção de competência" (BRASIL, 2015).

Maurício Ramires (2010, p. 47), ao criticar o instituto da reclamação, demonstra que este seria um atalho para a correção de supostas "desobediências" às teses firmadas pelas cortes superiores e, mais recentemente, também pelos demais tribunais. Estaremos diante de uma desigualdade, pois, se um juiz contrariar determinada lei ou mesmo dispositivo constitucional, desta decisão cabe recurso pelas vias ordinárias. De outro modo, caso sejam contrariadas as teses firmadas pelas cortes superiores ou pelos tribunais, caberá reclamação diretamente ao tribunal que a proferiu, como um atalho.

Os autores Didier Jr. e Cunha (2016) fazem menção a um microssistema de aplicação de precedentes, instituído pelo Novo Código de Processo Civil, a fim de assegurar a observância das teses jurídicas firmadas pelas Cortes Superiores. Como exemplo, estabelece o artigo 927, inciso III do NCPC que os acórdãos proferidos em incidente de assunção de competência ou em resolução de demandas repetitivas, assim como em recursos repetitivos, serão de observância obrigatória nos juízos inferiores.

\subsection{ANÁLISE CRÍTICA A PARTIR DO ESTUDO DE CASOS}

A terceira seção do Tribunal Regional Federal da $4^{a}$ Região julgou o Incidente de Resolução de Demandas Repetitivas número 12, firmando a tese jurídica de que a comprovação de renda per capita inferior a $\frac{1}{4}$ do salário mínimo gera presunção absoluta de miserabilidade, para fins de concessão do benefício assistência para manutenção da pessoa com deficiência, previsto na lei 8.742/93. 
A partir de então, fixada a tese jurídica, os juízos vinculados ao referido tribunal devem seguir o mesmo entendimento. Em relação à matéria em análise não há consenso quanto à fixação de critérios objetivos e absolutos para a concessão de benefício assistencial, vez que este é destinado a suprir um mínimo existencial à pessoa com necessidades, dependendo, para tanto, da análise de cada situação fática. Conforme decisão exarada em sede do Tribunal Regional Federal da $1^{\text {a }}$ Região, não se pode proibir o juízo de analisar o conjunto probatório do caso concreto por meio da fixação de critérios absolutos e intransponíveis, pois se está impedindo a atividade interpretativa do juiz (BRASIL, 2017a).

Tal efeito adverso da instituição de um sistema de precedentes "à moda brasileira", de maneira utilitarista, já fora previsto por Raatz (2016). Segundo o autor, a instituição de um sistema de precedentes permite a utilização de teses vinculantes, desde que fixadas por Cortes de Vértice (no caso em comento a utilização de um critério absoluto, frise-se sem análise do conjunto probatório, para definir quem possui direito ao benefício assistencial), simplesmente pela autoridade de quem a produziu, ainda que esta não seja a resposta mais acertada para o caso concreto. Portanto, o juiz, se deparando com uma situação concreta em que o requerente receba renda declarada inferior à $1 / 4$ do salário-mínimo, estará obrigado a conceder o benefício, ainda que se possa constatar, por outros meios, que este possui condições de prover a sua manutenção.

Em outro julgado, o Tribunal Regional Federal da $4^{a}$ Região analisou possivel ilegalidade da resolução $n^{\circ}$ 543/2015 do Conselho Nacional de Trânsito - CONTRAN, tendo em vista alegada extrapolação do seu poder regulamentar. Tratou a referida resolução acerca da obrigatoriedade da inclusão de aulas em Simulador de Direção Veicular para a formação de novos condutores. Foi dado ampla publicidade do incidente às instituições que detém conhecimento técnico da temática, para participarem como amicus curiae. Ao final, firmou-se tese jurídica no sentido da compatibilidade da resolução com o ordenamento jurídico, resultando na legalidade da obrigatoriedade de aulas em simulador de direção como requisito para a obtenção da Carteira Nacional de Habilitação - CNH (BRASIL, 2016).

O Superior Tribunal de Justiça, ao enfrentar a mesma matéria em sede de Recurso Especial, acordou que o CONTRAN não extrapolou os limites de seu poder regulamentar, citando diversos outros julgados da mesma turma, a fim de demonstrar a coerência do entendimento fixado pela Corte. Por essa razão, é possível concluir que a tese firmada pelo TRF da $4^{a}$ Região, em sede do IRDR ora em comento, estabelece um precedente que está de acordo com o entendimento perpetrado pelas Cortes Superiores, contribuindo para a segurança jurídica (BRASIL, 2017b).

Segundo Ramires (2010), os precedentes são úteis para a compreensão do direito, de modo que a interpretação é construída a partir do contexto em que estão inseridos os fatos em um determinado momento histórico. Não obstante, adverte que decisões que se limitam a reproduzir enunciado de súmula 
ou de teses jurídicas não são fundamentadas e podem resultar o engessamento do sistema, limitando a atividade interpretativa. Ademais, ressalta o autor que, no âmbito do common law, é realizada uma análise do caso concreto, cuja finalidade é identificar a semelhança do caso presente com o anteriormente julgado sob a ótica dos fatos, justamente o oposto do que se tem observado em muitos dos tribunais brasileiros.

Acerca da viabilidade de representação adequada, verifica-se que, no caso em análise, foi dada ampla publicidade ao incidente com o intuito de chamar à ação representantes que detém conhecimento técnico sobre o tema em litígio. Ademais, o relator determinou a comunicação a diversas entidades, tais como o Conselho Nacional de Trânsito e os Centros Estaduais (BRASIL, 2017b).

Tratam-se de medidas que visam garantir o devido processo legal, vez que há litigantes que foram excluídos da ação. Neste sentido, Abboud e Cavalcanti (2015) afirmam que o incidente poderá ser um mecanismo que contribuirá para a resolução de litígios em massa, entretanto, é necessária uma leitura interpretativa deste, com o objetivo de aplicá-lo constitucionalmente.

Na visão de Igor Raatz (2016), a corrente doutrinária que prega a instituição de um sistema de precedentes no direito brasileiro, embora o façam sob o fundamento de buscar a segurança jurídica, com a previsibilidade dos julgamentos, peca ao outorgar, ao Poder Judiciário, a função de estabelecer o sentido único ao direito, a partir do qual estariam os demais juízos vinculados ao entendimento emanado das "cortes de precedentes". Tais cortes teriam a competência de fixar textos com força de lei, os quais seriam aplicados por subsunção aos casos futuros. Assim, aqueles que defendem os precedentes deixam de lado a hermenêutica e chegam a sustentar que a segurança jurídica estaria garantida se uma corte superior desse a última palavra sobre o tema, ainda que esta seja possivelmente equivocada, como se fosse possivel aprisionar o sentido da norma.

De igual modo, para os autores Streck e Raatz (2016b), o problema central da teoria dos precedentes no direito brasileiro é a discricionariedade jurisdicional, pois permite que a interpretação da norma ocorra de modo deslocado do texto que the deu origem, possibilitando ao interprete escolher livremente o seu sentido. Assim, o precedente passa a ser valorizado mais pela autoridade da qual emana do que pelo seu conteúdo e na sequência deverá ser aplicado pelos demais juízos, devido ao seu efeito vinculante, ainda que possua fundamentação deficiente. Tratam-se de decisões forjadas para solucionar casos futuros, impedindo, desta forma, novas atribuições de sentido à norma. Entretanto, no âmbito do common law, os precedentes não nascem com a intenção de solucionar casos futuros, mas adquirem autoridade a partir de sua aplicação reiterada a novos casos, pois a comunidade jurídica entende que esta é a solução adequada a partir da análise de cada caso concreto e não por ser uma tese imposta pela autoridade de uma Corte Superior. 
Por todo o exposto, verifica-se que parcela da doutrina, dentre os quais Fredie Didier Jr., Sofia Temer, Luiz Guilherme Marinoni, Sérgio Cruz Arenhart, Daniel Mitidiero, entre outros, ainda que bem intencionada, sob o fundamento de garantir a segurança jurídica e a celeridade processual, acaba lançando mão de um sistema de precedentes, o qual outorga às Cortes Superiores a função de interpretar e fixar teses jurídicas a serem aplicadas de modo vinculante aos juízos inferiores. Ocorre que outra parcela significativa da doutrina, dentre os quais Lenio Streck, Georges Abboud, Júlio César Rossi, Igor Raatz, Maurício Ramires, entre outros, demonstra uma série de inconstitucionalidades, as quais estão a ferir o devido processo legal, o contraditório e a ampla defesa. Ademais, verifica-se que o uso indiscriminado de teses jurídicas firmadas por Cortes de Vértice nem mesmo estão em conformidade com o legítimo common law. Deste modo, conforme aponta a doutrina acima citada, deve-se fazer um esforço hermenêutico na tentativa de aplicar constitucionalmente os institutos em análise, a fim de garantir a representatividade, com a efetiva participação dos interessados e promover a observância dos demais princípios constitucionais do Estado Democrático de Direito.

\section{CONSIDERAÇÕES FINAIS}

É possível concluir que no sistema jurídico da common law, originário do direito inglês, predomina o elemento histórico e a valorização dos precedentes como meio de encontrar a resposta adequada para o caso concreto, enquanto que no âmbito do civil law, cuja base é o direito romano, predomina um ordenamento jurídico positivado com normas escritas, baseadas em uma Constituição e institutos legais codificados.

Mais recentemente, observou-se um movimento de recepção, no qual são incorporados ao ordenamento jurídico institutos advindos do direito estrangeiro, permitindo que mesmo países cuja base é o civil law, como no Brasil, importem mecanismos típicos do sistema jurídico da common law.

Com o advento do Novo Código de Processo Civil, parcela da doutrina passou a defender a instituição de um sistema de precedentes, nesse sentido, Luiz Guilherme Marinoni, Daniel Mitidiero, Fredie Didier Jr., entre outros. De modo contrário a essa corrente, os autores Lenio Streck, Igor Raatz, Nelson Nery Junior, entre outros, sustentam a inconstitucionalidade de se estabelecer, no Brasil, cuja base é o civil law, um sistema de precedentes com o intuito de vincular os juízos inferiores, a partir do julgamento de teses por Cortes de Vértice. Haja vista que se estaria outorgando ao Poder Judiciário a função de legislar.

Dentre os mecanismos trazidos pelo novo código encontra-se o Incidente de Resolução de Demandas Repetitivas, cujo objetivo é resolver em definitivo questão unicamente de direito, quando houver 
repetitividade de demandas. Observa-se que a partir do incidente será formada uma tese jurídica vinculante. Ocorre que, para isso, nem todos os jurisdicionados poderão participar efetivamente do julgamento, pois, uma vez instaurado, serão escolhidos dois casos representativos da controvérsia, os demais permanecerão suspensos aguardando a fixação da tese jurídica.

Por essas razões, doutrinadores como Lenio Streck, Igor Raatz, Maurício Ramires e Nelson Ney Junior, entre outros, demonstram inconstitucionalidades no pretenso sistema de precedentes "à moda brasileira", a partir da fixação de teses pelas Cortes de Vértice, as quais teriam a competência de tão somente interpretar a lei e formar teses jurídicas a serem aplicadas pelos juízos inferiores de modo vinculante e automático. Diferente do que ocorre no common law, no Brasil pretende-se impor teses jurídicas por Cortes Superiores, as quais teriam a competência unicamente de interpretar a lei, restringindo a interpretação dos demais juízos.

Assim, conforme aponta a doutrina acima citada, deve-se fazer um esforço hermenêutico na tentativa de aplicar constitucionalmente os institutos em análise, a fim de garantir a representatividade adequada dos interessados, com a efetiva participação dos demandantes, promovendo a observância dos demais princípios constitucionais do Estado Democrático de Direito.

Da análise dos dois incidentes de resolução de demandas repetitivas, realizada neste estudo, percebese que o primeiro deles, o qual tratou da fixação de critérios absolutos para auferir a miserabilidade do requerente, a fim de conceder o benefício assistencial, não se constatou uma efetiva representatividade dos interesses envolvidos, ademais, se impôs um entendimento que nem mesmo há consenso na doutrina ou jurisprudência, impedindo os juízes inferiores de analisar o conjunto probatório de cada caso concreto.

De outro modo, verifica-se que o IRDR que tratou dos simuladores de direção veicular, IRDR $n^{\circ}$ 5024326-28.2016.4.04.0000/PR, propôs um diálogo entre diversas entidades representativas de categorias interessadas, ao final, estabeleceu uma tese jurídica que vai ao encontro do entendimento emanado do Superior Tribunal de Justiça sobre o tema. Assim, verifica-se que este último caso contribui para a unidade e coerência do direito, produzindo um julgamento que garantiu a representatividade adequada das partes excluídas do litígio, garantindo o devido processo legal.

Conclui-se, portanto, que o incidente de resolução de demandas repetitivas, embora seja um mecanismo destinado à formação de precedentes, não possui o condão de modificar a tradição jurídica brasileira, que permanece assentada na família de direitos da civil law. Desta forma, não é possível que o Novo Código de Processo Civil, uma lei ordinária, acarrete na "commonlawlização" do direito brasileiro. Por essas razões, é necessária uma leitura hermenêutica dos institutos aqui analisados, a fim de permitir que estes contribuam para a uniformização da jurisprudência e celeridade processual, sem que, no entanto, restrinjam o princípio do contraditório e da ampla defesa, garantindo, assim, a efetividade do devido processo legal. 


\section{REFERÊNCIAS}

ABBOUD, Georges; CAVALCANTI, Marcos de Araújo. Inconstitucionalidades do Incidente de Resolução de Demandas Repetitivas (IRDR) e os riscos ao sistema decisório. Revista de Processo: RePro. São Paulo: v. 240, p. 221-224, fev. 2015. Disponivel em: <http:/www.revistadostribunais.com.br/maf/app/resultList/ document?\&src=rl\&srguid=iOad6adc6000001639947e1771b810585\&docguid=l09b13880a13711e4 bb01010000000000\&hitguid=I09b13880a13711e4bb01010000000000\&spos $=1$ \&epos $=1 \& t d=59 \&-$ context=11\&crumb-action=append\&crumb-label=Documento\&isDocFG=true\&isFromMultiSumm=true\&startChunk=1\&endChunk=1 >. Acessado em: 25 maio 2018.

ABBOUD, Georges. Discricionariedade administrativa e judicial: o ato administrativo e a decisão judicial. São Paulo: Revista dos Tribunais, 2014.

ALVES, José Carlos Moreira. Direito Romano. 17. ed. Rio de Janeiro: Editora Forense, 2016.

BRASIL, Presidência da República. Lei n 13.105, de 16 de março de 2015.Estabelece o novo código de processo civil. Disponível em: < http://www.planalto.gov.br/ccivil_03/_ato2015-2018/2015/lei//13105 htm>. Acesso em: 18 nov. 2017.

Tribunal Regional Federal da $4^{\mathrm{a}}$ Região. Incidente de Resolução de Demandas Repetitivas $\mathbf{n}^{\circ}$ 5013036-79.2017.4.04.0000/RS. Disponivel em: <https://www2.trf4.jus.br/trf4/controlador.php?acao=consulta_processual_resultado_pesquisa\&selForma=NU\&txtValor $=50130367920174040000 \&-$ chkMostrarBaixados $=\&$ todasfases $=\&$ todosvalores $=\&$ todaspartes $=\&$ txtDataFase $=01 / 01 / 1970 \&$ se IOrigem=TRF\&sistema=\&hdnRefld=\&txtPalavraGerada=\&txtChave=>. Acessado em: 16 maio 2018.

Tribunal Regional Federal da $4^{a}$ Região. Incidente de Resolução de Demandas Repetitivas nº 5024326-28.2016.4.04.0000/PR. Relatora Marga Inge Barth Tessler. Data do julgamento: 18/10/17. Disponivel em: <https://www2.trf4.jus.br/trf4/controlador.php?acao=consulta_processual_resultado_ pesquisa\&selForma=NU\&txtValor=50243262820164040000\&chkMostrarBaixados=\&todasfases $=\&-$ todosvalores $=\&$ todaspartes $=\&$ txtDataFase $=\&$ selOrigem $=$ TRF \&sistema $=\&$ hdnRefld $=\&$ txtPalavraGera da $=\&$ txtChave $=>$. Acessado em: 16 maio 2018.

DAVID, René. Os grandes sistemas de direito contemporâneo. Traduzido por Hermínio A. Carvalho. 5. ed. São Paulo: Martins Fontes, 2014.

DIDIER JÚNIOR, Fredie. Curso de Direito Processual Civil. 2. ed. Salvador: JusPodivm, 2008.

DIDIER JÚNIOR, Fredie; CUNHA, Leonardo Carneiro da. Curso de Direito Processual Civil: Meios de impugnação às decisões judiciais e processos nos Tribunais. v. 3. 13. ed. Salvador: JusPodivm, 2016. 
GILISSEN, John. Introdução histórica ao direito. Traduzido por A.M. Hespanha e L.M. Macaísta Malheiros. 7. ed. Lisboa: Fundação Calouste Gulbenkian, 2013.

KELSEN, Hans. Teoria Pura do Direito. Traduzido por João Baptista Machado. 8. ed. São Paulo: WMF Martins Fontes, 2009.

MARIONI, Luiz Guilherme. A ética dos precedentes: justificativa do novo CPC. 2. ed. rev. atual e ampl. São Paulo: Editora Revista dos Tribunais, 2016.

MARINONI, Luiz Guilherme. Incidente de resolução de demandas repetitivas: Decisão de questão idêntica x precedente. São Paulo: Revista dos Tribunais, 2016.

MERRYMAN, John Henry. La tradición juridical romano-canónica. Traduzido por Carlos Sierra. 2. ed. México: FCE, 1989.

MITIDIERO, Daniel. Precedentes: da persuasão à vinculação. 2. ed. rev. e atual. São Paulo: Revista dos Tribunais, 2017.

NERY JUNIOR, Nelson; NERY, Rosa Maria Andrade. Código de processo civil comentado. 2. ed. São PauIo: Revista dos Tribunais, 1996.

NERY JUNIOR, Nelson; NERY, Rosa Maria de Andrade. Comentários ao código de processo civil. In: HARMS, Maria (Dir.). São Paulo: Revista dos Tribunais, 2015.

NEVES, António Castanheira. Curso de introdução ao estudo do direito. Coimbra: J. Abrantes, 1972.

NUNES, Jorge Amaury Maia. Segurança jurídica e súmula vinculante. São Paulo: Saraiva, 2010.

OLIVEIRA, Paulo Mendes de. Coisa Julgada e precedente: limites temporais e as relações jurídicas de trato continuado. In: MARINONI, Luiz Guilherme. (Dir.); ARENHART, Sergio Cruz; MITIDIERO, Daniel (Coord.). São Paulo: Revista dos Tribunais, 2015. (Coleção o novo processo civil)

RAATZ, Igor. Precedentes à brasileira: uma autorização para "errar" por último?. Revista Consultor Jurídico. out. 2016. Disponivel em: <https://www.conjur.com.br/2016-out-03/igor-raatz-precedentes-autorizacao-errar-ultimo>. Acessado em: 20 nov. 2017.

RAMIRES, Maurício. Crítica à aplicação de precedentes no direito brasileiro. Porto Alegre: Livraria do Advogado Editora, 2010.

REALE, Miguel. Lições preliminares do direito. 27. ed. São Paulo: Saraiva, 2014. 
REIS, Nazareno César Moreira. Súmula "vinculante": uma petição de princípio. Revista Justiça do Trabalho. Porto Alegre, ano 22, n. 254, fev. 2005, disponivel em: <http://siabi.trt4.jus.br/biblioteca/direito/ doutrina/artigos/Revista_Eletronica/2005/Revista Eletrônica n. 2 art.2_2005.pdf>. acessado em: 28 out. 2017.

ROSSI, Júlio César. Precedentes à brasileira: a jurisprudência vinculante no CPC e Novo CPC. São Paulo: Atlas, 2015.

SCHEID, Carlos Eduardo. A motivação das decisões penais: a partir da teoria garantista. Porto Alegre: Livraria do Advogado Editora, 2009.

SILVEIRO, João Paulo Santos. O sistema de precedentes à luz do novo CPC: análise do julgamento paradigmático sobre a comissão de corretagem. In: WAMBIER, Teresa Arruda Alvim. (Coord.). Revista Jurídica. São Paulo, Ano 65, n. 475, fev. 2017.

STRECK, Lenio Luiz; ABBOUD Georges. $\mathbf{0}$ que é isto - o precedente judicial e as súmulas vinculantes?. 3. ed. ver. e atual. Porto Alegre: Livraria do Advogado, 2015, p. 38. (Coleção o que é isto? - 3)

STRECK, Lenio Luiz. Por que commonlistas brasileiros querem proibir juízes de interpretar?. Revista Consultor Jurídico. Set. 2016. Disponível em: < http://www.conjur.com.br/2016-set-22/senso-incomum-commonlistas-brasileiros-proibir-juizes-interpretar> Acesso em 22 Set. 2016.

STRECK, Lenio Luiz; RAATZ, Igor. A Teoria dos precedentes à brasileira entre o solipsismo judicial e o positivismo jurisprudencialista ou "de como o mundo (não) é um brechó". In: ALVIM, Teresa Arruda (Coord.). Revista de Processo REPro. São Paulo: ano. 41, vol. 262, dez de 2016.

TEMER, Sofia. Incidente de resolução de demandas repetitivas. Salvador: JusPodivm, 2016.

ZANETI JR., Hermes. $\mathbf{O}$ valor vinculante dos precedentes. 2. ed. rev. e atual. Salvador: Editora Jus Podivm, 2016. 